\title{
Bursa Bölgesinde Alerjik Astım Tanılı Çocuklarda Ağaç Polen Alerjenlerine Duyarlıık Oranlarının Araştırılması
} Investigation of Sensitivity Rates to Tree Pollen Allergens in
Children with Allergic Asthma in Bursa Region

Yakup Canıtez (0000-0001-8929-679X), Şükrü Çekiç (0000-0002-9574-1842)

Bursa Uludağ Üniversitesi Tıp Fakültesi, Çocuk Alerji Bilim Dalı, Bursa, Türkiye

Anahtar kelimeler

Astım, alerjik astım, çocuk, alerjen,

duyarlılık, deri prik test

Keywords

Asthma, allergic asthma, child, allergen, sensitivity, skin prick test

Geliş Tarihi/Received : 01.03.2021

Kabul Tarihi/Accepted : 22.03.2021

DOI:10.4274/jcp.2021.0010

Yazışma Adresi (Sorumlu Yazar)/Address for Correspondence:

Dr. Yakup Canıtez, Bursa Uludağ Üniversitesi Tıp Fakültesi, Çocuk Alerji Bilim Dalı, Bursa, Türkiye

\section{$\ddot{\mathbf{O z}}$}

Giriş: Alerjik astım tanılı çocuk olgularda ağaç polenleri alerjenlerine karşı duyarlılık oranlarının, ağaç polen duyarlılığına etki eden çeşitli faktörlerin araştırılması amaçlanmıştır.

Gereç ve Yöntem: Çalışmaya alerjik astım tanılı 5-18 yaş arası 560 çocuk olgu alındı. Olguların klinik, laboratuvar ve deri prik testi verileri retrospektif olarak incelendi.

Bulgular: Çalışmada yer alan olgularda deri prik testlerinde, ağaç polen alerjenlerine genel duyarlılık [Olea europeae (Zeytin ağac1), Alnus glutinosa (kızıl ağaç), Platanus acerifolia (Çınar ağacı), Corylus avellena (Fındık ağacı), Betula verrucosa (Huş ağacı), Pinus silvestris (Sarıçam ağacı)]' den en az birine duyarlılık varlığı) oranı \%17,7 olarak saptandı. Diğer alerjen duyarlılıkları; akarlar \% 75,0, çimen polenleri $\% 47,3$, tahıl polenleri $\% 39,5$, yabani ot polenleri $\% 18,4$, kedi ve/ veya köpek \%13,4, mantarlar \%12,9, hamam böceği \%6,1 olarak bulundu. Ağaç polen alerjenlerine genel duyarlılık oranlarının 5-8 yaş grubunda $(\% 9,5), 9-13$ yaş grubunda $(\% 20,7), 14-18$ yaş grubunda $(\% 28,8)$ oranlarında bulunduğu ve yaş ile paralel artış gösterdiği saptandı $(\mathrm{p}<0,001)$. Ağaç polenleri genel duyarlılığının, eşlik eden alerjik rinit veya alerjik konjonktivit varlığında daha yüksek oranlarda görüldüğü (sırasıyla p=0,019, p=0,002), akar duyarlılığı varlığında ise daha düşük oranda görüldüğü $(\mathrm{p}<0,001)$ bulundu .

Sonuç: Bu çalışmada 5-18 yaş alerjik astımlı çocuklarda ağaç polen duyarlılığı oranları dikkate değer bir oranda saptanmıştır. A ğaç polen ve diğer alerjen duyarlılıkları ile ilgili alerjik astımlı çocuklardan elde edilen bu veriler, hastaların tanı ve tedavi yaklaşımlarında göz önünde bulundurulmalıdır.

\begin{abstract}
Introduction:It was aimed to investigate the sensitivity rates against tree pollen allergens and various factors affecting tree pollen sensitivity in children with allergic asthma.

Materials and Methods: 560 children aged 5-18 years with a diagnosis of allergic asthma were included in the study. Clinical, laboratory, and skin test data of the cases were analyzed retrospectively.

Results: In skin prick tests of the cases included in the study, the rate of general sensitivity to tree pollen allergens [presence of sensitivity to at least one of Olea europeae (olive), Alnus glutinosa (alder), Platanus acerifolia (plane), Corylus avellena (hazel), Betula verrucosa (birch), Pinus silvestris (pine)] was found to be $17.7 \%$. Other allergen sensitivities; mites $75.0 \%$, grass pollen $47.3 \%$, grain pollen $39.5 \%$, weed pollen $18.4 \%$, cat and/or dog $13.4 \%$, fungi $12.9 \%$, cockroach $6.1 \%$ was determined. It was found that the general sensitivity rates to tree pollen allergens were in the 5-8 age group (9.5\%), the 9-13 age group (20.7\%), the 1418 age group $(28.8 \%)$ and increased in parallel with age $(\mathrm{p}<0,001)$. Tree pollen
\end{abstract}


sensitivity was found to be higher in the presence of concomitant allergic rhinitis or allergic conjunctivitis $(\mathrm{p}=0.019, \mathrm{p}=0.002$, respectively), and lower in the presence of mite sensitivity $(\mathrm{p}<0.001)$.

Conclusions: In this study, tree pollen sensitivity rates were remarkable in children aged 5-18 years with allergic asthma. The data on tree pollen and other allergen sensitivities obtained from children with allergic asthma should be considered in the diagnosis and treatment approaches of the patients.

\section{Giriş}

Astım genetik ve çevresel faktörlerin ortak etkisiyle ortaya çıkan çocukluk çağının en sık kronik inflamatuvar solunum yolu hastalığıdır. Çocukluk çağında astım görülme sıklığı ülkeden ülkeye hatta aynı ülkenin değişik bölgelerinde farklılıklar gösterebilmektedir $(1,2)$. Çocukluk çağı astımının genel olarak yaklaşık \%70-80 oranlarında alerjik (atopik) astım olarak tanımlandığ $(3,4)$.

Alerjenler, çocukluk çağında alerjik astım, alerjik rinit ve alerjik konjonktivitte semptomları ortaya çıkaran en önemli çevresel etkenlerdir. Çocukluk çağında alerjik astımlı olgularda saptanan alerjen duyarlılıkları içinde; akarlar, çeşitli bitki polenleri (çimen, tahıllar, ağaçlar, yabani otlar), mantar alerjenleri sık saptanan inhalan alerjenlerdir. Ayrica kedi ve hamam böceği alerjenleri de etken olan inhalan alerjenler olarak bildirilmektedir. Hastalarda görülen alerjen duyarlılıkları; iklim, bitki örtüsü, nem oranı, coğrafi özellikler, yaşam koşulları gibi çevresel faktörlere bağlı olarak bölgeler ve ülkelere göre farkl1lıklar göstermektedir (2,5).

Ağaç polenlerinin atmosferde yüksek düzeyde bulunduğu aylar, bölgesel ve iklimsel farklılıklara göre çeşitlilikler göstermektedir, Türkiye'nin Marmara ve Batı bölgelerinde birçok ağaç için polinizasyon (tozlaşma) miktarlarının genellikle Şubat ve Nisan ayları arasında atmosferde en yüksek düzeyde görüldüğü bildirilmektedir (6-8). Ancak bazı ağaçlarda bu durum farklıdır. Örneğin; atmosferde polen yoğunlukları Platanus (çınar ağacı) polenleri için nisan-mayıs aylarında, Olea europeae (zeytin ağacı) polenleri için ise mayıs ve haziran aylarında en yüksek seviyededir $(9,10)$.

Alerjen ile temas sonrasi alerjene spesifik immunglobulin (Ig) IgE oluşması veya deri prik testinde duyarlılık saptanması "atopi" olarak tanımlanmaktadır (3). Atopi varlığ 1 , astım gelişme riskini 10-20 kat arttırmaktadır (11). Deri prik testleri, çeşitli alerjenlere karşı var olan Tip 1 (IgE aracılıklı) aşırı duyarlılık reaksiyonunu gösteren in vivo bir testtir. Deri testleri ile alerjenlere karşı duyarlılığın varlığ 1 ve derecesi belirlenebilir $(12,13,14)$.

Alerjik astım, alerjik rinit ve alerjik konjonktivitte birçok ülke ve bölgede yapılan çalışmalarda bitki polenleri içinde çimen polenleri en sik alerjen duyarlılığının saptandığı bildirilen ve üzerinde en çok araştırma yapılmış olan gruptur. Ancak çocukluk çağında alerjik astımlı olgularda spesifik olarak ağaç polen alerjenlerine karşı duyarlılık oranlarını ve ilişkili faktörleri araştırmaya odaklanmış çalışmalar az sayıdadır.

Bu nedenlerle Türkiye'nin Marmara bölgesinde yer alan Bursa bölgesinde, alerjik astım tanısı almış olan çocukluk çağındaki olgularda ağaç polen alerjenleri ve diğer yaygın inhalan alerjenlere karşı duyarlılık oranlarının, ağaç polen duyarlılığına etki eden çeşitli faktörlerin (cinsiyet, yaş vb.) saptanması, eşlik eden diğer alerjik hastalıkların, diğer alerjen duyarlılıklarının birlikte görülme oranlarının araştırılması amacı ile bu çalışma planlanmıştır.

\section{Gereç ve Yöntem}

Bursa Uludağ Üniversitesi Tip Fakültesi Çocuk Alerji Bilim Dalı Polikliniği’nde 01.01.201130.12.2015 tarihleri arasında Astım için Küresel Girişim (Global strategy for asthma management and prevention - GINA) (15) kriterlerine göre astım tanısı almış ve yaygın alerjenlerle deri prik testlerinde en az bir inhalan alerjene duyarlılık saptanarak alerjik astım olarak tanımlanmış olan 5-18 yaş arası 560 olgu çalışmaya alındı.

Tüm hastaların yaş (hastanın son değerlendirildiği yaş), cinsiyet, astım semptomlarının başlangıç yaşı, eşlik eden diğer alerjik hastalıklar varlığ alerjenlerle deri prik test sonuçları retrospektif olarak incelendi. 


\section{Alerjenlerle Deri Prik Testleri}

Alerjenlerle deri prik (epidermal) testleri, ALKAbello (Horsholm, Denmark) standart alerjen ekstreleri ile ve tek kullanımlık Stallerpoint plastik lansetler (Stallergenes, Antony, France) kullanilarak Çocuk Alerji Bilim Dalı Laboratuarında uygulanmıştı. Yaygın alerjenlerle deri prik testlerinde, standart rutin uygulama gereği alerjenler her iki ön kolun volar yüzüne birbirinden en az $3 \mathrm{~cm}$ aralıklı şekilde damlatıldıktan sonra her alerjen için ayrı tek kullanımlık plastik lanset kullanılarak deri içine (epidermal) uygulandı. Pozitif kontrol olarak histamin \% 0,1 (1 mg/ml) ve negatif kontrol olarak serum fizyolojik kullanıldı. Alerjenler uygulandıktan $15 \mathrm{dk}$ sonra negatif kontrole kiyasla $3 \mathrm{~mm}$ veya daha fazla ödem saptandığında deri testi sonuçları pozitif kabul edildi (16).

Yaygın alerjenlerle deri prik testlerinde kliniğimizde 5 yaş ve üstü tüm hastalara standart test listesi olarak uygulanan, tekli olarak çalışılan inhalan alerjenler (toplam 25 alerjen) aşağıda belirtilmiştir.

a) Ağaç polenleri; Olea europeae (Zeytin ağac1), Alnus glutinosa (Kızılağaç), Platanus acerifolia (Çınar ağacı), Corylus avellena (Fındık ağacı), Betula verrucosa (Huş ağac1), Pinus silvestris (Sarıçam ağacı),

b) Akarlar; Dermatophagoides pteronyssinus, Dermatophagoides farinae,

c) Çimen polenleri; Cynodon dactylon, Dactylis glomerata, Lollium perenne, Phleum pratense

d) Tahıl polenleri; Secale cereale, Avena sativa, Triticum sativum,

e) Yabani ot polenleri; Artemisia vulgaris, Chenopodium album, Plantago lanceolata, Pariteria judaica,

f) Mantar sporlar1; Alternaria alternata, Cladosporium herbarum, Aspergillus fumigatus,

g) Evcil hayvanlar; Kedi (Felis domesticus), Köpek (Canis familiaris),

h) Hamam böceği; Blatella germanica.

Deri prik testi sonuçlarına göre en az bir alerjene karşı duyarlılık saptanan olgular alerjik (atopik) olarak kabul edildi (16). Ayrıca deri prik testi sonuçları alerjen gruplarına göre gruplandırıldı; ağaç polenleri genel duyarlılı̆̆ı; ağaç polen türleri içinde en az bir tür ağaç polenine karşı duyarlılık saptanması durumu olarak tanımlandı. Benzer şekilde diğer alerjenler içinde o gruba ait genel duyarlılık sonuçları belirlendi; çimen polenleri genel duyarlılığ 1 , tahıl polenleri genel duyarlılığı, yabani ot polenleri genel duyarlılığ 1 , akar genel duyarlılı $\breve{g} 1$, mantar genel duyarlılığ için o grupta yer alan en az bir alerjene karşı duyarlılık saptanması durumu olarak tanımland.

Çalışma için Bursa Uludağ Üniversitesi Tıp Fakültesi Klinik Araştırmalar Etik Kurulu'ndan onay alınmıştır.

\section{Istatistiksel Analiz}

Değişkenler ortalama \pm standart sapma değerleriyle ifade edilmiştir. Sürekli değişkenlerin normal dağılıma uygunluğu Kolmogorov Smirnov testi ile incelenmiştir. Normallik testi sonucuna göre nicel verilerin karşılaştırılmasında bağımsız çift örneklem $\mathrm{T}$ testi veya Mann-Whitney $\mathrm{U}$ testi kullanılmıştır. Kategorik değişkenler ise $\mathrm{n}(\%)$ olarak ifade edilmiş olup bağımsız değişkenler için Pearson Ki-kare testi kullanılmıştır. Analizler SPSS (IBM Corp. Released 2015. IBM SPSS Statistics for Windows, Version 23.0. Armonk, NY: IBM Corp.) programında yapılmış olup, $p$ değeri 0,05 'in altında anlamlı olarak kabul edilmiştir.

\section{Bulgular}

Çalışma grubunda yer alan alerjik astımlı tüm olguların (560 olgu), genel özellikleri Tablo 1'de verilmiştir. Alerjik astımlı olguların \%58,2'si erkek ve $\% 41,8$ 'i k1z, ortalama yaşları 10,4 $\pm 3,5$ y1l (5-18 y1l, erkekler 10,1 $\pm 3,5$, kızlar 10,8 $\pm 3,6)$, alerjik astım semptomlarının başlangıç yaşı 5,3 3,6 yıl $(0-17$ yaş) idi. Olguların \%36,4'ü 5-8 yaş, \%40,4'ü 9-13 yaş, \%23,2'si 14-18 yaş grubunda bulunmaktaydı (Tablo 1).

Tablo 1. Çalışmada grubundaki alerjik astımlı olguların genel özellikleri $(n=560)$

\begin{tabular}{|c|c|c|}
\hline & Olgu sayısı (n) & $(\%)$ \\
\hline \multicolumn{3}{|l|}{ Cinsiyet } \\
\hline Erkek & 326 & $\% 58,2$ \\
\hline $\mathrm{K} 1 \mathrm{z}$ & 234 & $\% 41,8$ \\
\hline \multicolumn{3}{|l|}{ Yaş grupları } \\
\hline $5-8$ yaş & 232 & 36,4 \\
\hline 9-13 yaş & 217 & 40,4 \\
\hline $14-18$ yaş & 111 & 23,2 \\
\hline Yaş (yıl) & $10,4 \pm 3,5(5-18)$ & \\
\hline Semptomların başlangıç yaşı (yıl) & $5,3 \pm 3,6(0-17)$ & \\
\hline Tanı yaşı (yıl) & $8,1 \pm 3,4(1-17)$ & \\
\hline İzlem süresi (yıl) & $2,25 \pm 2,4(0-15)$ & \\
\hline
\end{tabular}


Alerjik astımlı çocuklarda $(n=560)$ deri prik testleriyle ağaç polen alerjenlerine genel duyarlılık (deri prik testi yapılmış olan 6 ayrı ağaç polen alerjeni; Olea europeae, Alnus glutinosa, Platanus acerifolia, Corylus avellena, Betula verrucosa, Pinus silvestris' den en az birine duyarlılı) oran1 \%17,7 (n=99) olarak saptandı (Tablo 2). Alerjik astımlı olgularda deri prik testi ile çeşitli alerjen gruplarına karşı saptanan duyarlılık oranları Tablo 2'de alerjen gruplarına göre belirtilmiştir. Tüm alerjen grupları içinde en yüksek oranda (\%75) akar alerjenlerine (Dermatophagoides pteronyssinus ve/veya Dermatophagoides farinae) duyarlılık saptandığı gözlendi. Çimen polenleri genel duyarlılığı (Cynodon dactylon, Dactylis glomerata, Lolium perenne, Phleum pratense alerjenlerinden

Tablo 2. Alerjik astımlı olgularda çeşitli alerjen gruplarına karşı saptanan duyarlılık oranları $(\mathrm{n}=560)$

\begin{tabular}{llll}
\hline Alerjenler & $\begin{array}{l}\text { Test yapılan } \\
\text { olgu sayısı }\end{array}$ & $\begin{array}{l}\text { Duyarlı } \\
\text { olan olgu } \\
\text { sayısı }\end{array}$ & $\%$ \\
\hline Ağaç polenleri genel* & 560 & 99 & 17,7 \\
Çimen polenleri genel* & 560 & 265 & 47,3 \\
Tahıl polen genel* & 560 & 221 & 39,5 \\
Yabani ot polen genel* & 560 & 103 & 18,4 \\
Akar genel* & 560 & 420 & 75,0 \\
Mantarlar genel* & 560 & 72 & 12,9 \\
Kedi ve/veya köpek & 560 & 75 & 13,4 \\
Hamam böceği & 545 & 33 & 6,1 \\
\hline *: Bu gruptaki alerjenlerden en az birine karşı duyarlılık varlı̆̆ \\
\hline
\end{tabular}

en az birine karşı duyarlılık varlığ 1 ) \%47,3 oranı ile 2. sırada saptanmıştı (Tablo 2). Çimen polenlerini sirasıly; tahil polenleri $(\% 39,5)$, yabani ot polenleri $(\% 18,4)$, ağaç polenleri $(\% 17,7)$, evcil hayvanlar (kedi ve/veya köpek) $(\% 13,4)$, mantar alerjenleri $(\% 12,9)$ genel duyarlılıkları, hamam böceği $(\% 6,1)$ şeklinde sıklık sırasına göre izlediği saptandı (Tablo 2).

Çalışma grubundaki tüm olgularda $(n=560)$, çeşitli alerjen gruplarına karşı saptanan duyarlılık oranları, yaş gruplarına (5-8, 9-13, 14-18 yaş grupları) göre ayrı ayrı incelendiğinde (Tablo 3), ağaç polen alerjenlerine duyarlılık oranlarının 5-8 yaş grubunda $(\% 9,5), 9-13$ yaş grubunda $(\% 20,7), 14-18$ yaş grubunda $(\% 28,8)$ oranında saptandığı ve yaş ile paralel artış gösterdiği saptand $1(p<0,001)$ (Tablo 3). Benzer şekilde çimen polenleri, tahıl polenleri, yabani ot polenleri duyarlılık oranlarının da istatistiksel anlamlı yaş ile paralel artış gösterdiği saptandı (sırasıyla $\mathrm{p}<0,001, \mathrm{p}<0,001$, $\mathrm{p}<0,001)$. Akarlar ve mantar alerjenleri duyarlılı̆ için ise yaş gruplarına göre belirgin farklılık mevcut değildi (sırasiyla $\mathrm{p}=0,076, \mathrm{p}=0,442$ ) (Tablo 3).

Alerjik astımlı olgularda ağaç polen genel duyarlılı̆̆ (en az bir ağaç alerjenine duyarlılık) olan ve olmayan olguların çeşitli özelliklerinin karşılaştırıldığında (Tablo 4); kız veya erkek cinsiyetin ağaç polen genel duyarlılığ varlığ üzerinde anlamlı etkisi saptanmamıştır $(\mathrm{p}=0,654)$. Alerjik rinit veya konjonktivit varlığında ise ağaç polen genel duyarlılığının istatistiksel anlamlı olarak daha yüksek oranda görüldüğ̈̈ saptanmıştır (sırasıyla $\mathrm{p}=0,019$, $\mathrm{p}=0,002)$. Ağaç polen genel duyarlılığı varlığında çimen, tahıl ve yabani otlar polen genel duyarlılıklarının

Tablo 3. Çalışma grubundaki tüm alerjik astımlı olgularda $(n=560)$, yaş gruplarına göre deri prick testi ile çeşitli alerjen gruplarına karşı saptanan duyarlılık oranları

\begin{tabular}{|c|c|c|c|c|c|c|c|}
\hline \multirow[t]{2}{*}{ Alerjenler } & \multicolumn{2}{|c|}{$\begin{array}{l}5-8 \text { yaş } \\
(n=232)\end{array}$} & \multicolumn{2}{|c|}{$\begin{array}{l}9-13 \text { yaş } \\
(n=217)\end{array}$} & \multicolumn{2}{|c|}{$\begin{array}{l}14-18 \text { yaş } \\
(\mathrm{n}=111)\end{array}$} & \multirow[b]{2}{*}{$\mathrm{p}$} \\
\hline & $\mathrm{n}$ & $\%$ & $\mathrm{n}$ & $\%$ & $\mathrm{n}$ & $\%$ & \\
\hline A ğaç polenleri genel* & 22 & 9,5 & 45 & 20,7 & 32 & 28,8 & $<0,001$ \\
\hline Çimen polenleri genel* & 77 & 33,2 & 113 & 52,1 & 75 & 67,6 & $<0,001$ \\
\hline Tahıl polenleri genel* ${ }^{*}$ & 58 & 25 & 92 & 42,4 & 71 & 64 & $<0,001$ \\
\hline Yabani ot polen genel* & 17 & 7,3 & 49 & 22,6 & 37 & 33,3 & $<0,001$ \\
\hline Akar genel* & 184 & 79,3 & 152 & 70 & 84 & 75,7 & 0,076 \\
\hline Mantarlar genel* & 25 & 10,8 & 32 & 14,7 & 15 & 13,5 & 0,442 \\
\hline Kedi ve/veya köpek & 19 & 8,2 & 33 & 15,2 & 23 & 20,7 & 0,004 \\
\hline Hamam böceği & 7 & 3,1 & 19 & 8,9 & 7 & 6,5 & $\mathbf{0 , 0 3 5}$ \\
\hline
\end{tabular}


en yüksek oranlarda saptandı $\breve{g} 1$ (sirasıyla \%90,9 $\% 84,8, \% 56,6)$ görülmüştür. Genel olarak Akarlar genel duyarlılığı ise ağaç polen duyarlılığ1 varlığ1 olan grupta anlamlı olarak daha düşük oranda bulundu $(p<0,001)$. Diğer inhalan alerjen duyarlılıkları ise ağaç polen duyarlılığ varlığı olan grupta anlamlı oranda daha yüksek oranlarda saptandı $(\mathrm{p}<0,001)$ (Tablo 4).

Çalışmada yer alan 560 alerjik astımlı olgu eşlik eden diğer tanılarına göre gruplara ayrıldığında; sadece alerjik astımı olanlar grubunda $313(\% 55,9)$ olgu, astım + alerjik rinit tanılı grubda $246(\% 43,9)$ olgu, astım + alerjik rinit + alerjik konjonktivit tanılı grupda 71 olgu $(\% 12,7)$ bulunduğu saptandı (Tablo
5). Alerjik astıma en sık alerjik rinit $(n=246, \% 43,9)$, ikinci surada alerjik rinit + konjonktivit $(\mathrm{n}=71, \% 12,7)$ eşlik etmekteydi (Tablo 5).

Sadece alerjik astım tanısı olan (eşlik eden alerjik rinit veya konjonktivit tanısı olmayan) grupta $(n=313)$; ağaç polen alerjenlerine duyarlılık (6 ayrı ağaç polen alerjeni; Olea europeae, Alnus glutinosa, Platanus acerifolia, Corylus avellena, Betula verrucosa, Pinus silvestris' den en az birine duyarlılık) oranı \%14,3 oranında saptandı (Tablo 5). Ağaç polenleri içinde en sik Olea europeae (\%14) duyarlılı̆̆ı, sonra sirasıyla, Betula verrucosa $(\% 2,8)$, Alnus glutinosa $(\% 2,1)$, Corylus avellena $(\% 2,1)$, Platanus acerifolia $(\% 1,4)$,

Tablo 4. Alerjik astımlı olgularda $(n=560)$ ağaç polen duyarlılığı olan ve olmayan olguların çeşitli özelliklerinin karşılaştırılması

\begin{tabular}{|c|c|c|c|c|c|c|c|}
\hline \multirow[t]{2}{*}{ Özellikler } & & & \multicolumn{2}{|c|}{$\begin{array}{l}\text { Ağaç polenleri genel } \\
\text { duyarlılığı }(-)(n=461)\end{array}$} & \multicolumn{2}{|c|}{$\begin{array}{l}\text { Ağaç polenleri genel } \\
\text { duyarlılığı }(+)(n=99)\end{array}$} & \multirow[b]{2}{*}{$\mathrm{p}$} \\
\hline & & & $\mathrm{n}$ & $\%$ & $\mathrm{n}$ & $\%$ & \\
\hline \multicolumn{3}{|l|}{ Alerjik rinit varlığ } & 192 & 41,6 & 54 & 54,5 & 0,019 \\
\hline \multicolumn{3}{|l|}{ Alerjik konjonktivit varlığg } & 50 & 10,8 & 22 & 22,2 & 0,002 \\
\hline \multicolumn{3}{|l|}{ Çimen polenleri genel* } & 175 & 37,9 & 90 & 90,9 & $<0,001$ \\
\hline \multicolumn{3}{|l|}{ Tahıl polenleri genel* } & 137 & 29,7 & 84 & 84,8 & $<0,001$ \\
\hline \multicolumn{3}{|l|}{ Yabani ot polen genel* } & 47 & 10,2 & 56 & 56,6 & $<0,001$ \\
\hline \multicolumn{3}{|l|}{ Akar genel* } & 369 & 80 & 51 & 51,3 & $<0,001$ \\
\hline \multicolumn{3}{|l|}{ Mantarlar genel* } & 46 & 9,9 & 26 & 26,3 & $<0,001$ \\
\hline \multicolumn{3}{|l|}{ Kedi ve/veya köpek } & 43 & 9,3 & 32 & 32,3 & $<0,001$ \\
\hline \multicolumn{3}{|l|}{ Hamam böceği } & 17 & 3,8 & 16 & 16,5 & $<0,001$ \\
\hline Cinsiyet & \multicolumn{2}{|c|}{$\begin{array}{l}\text { Kiz } \\
\text { Erkek }\end{array}$} & $\begin{array}{l}195 \\
266\end{array}$ & $\begin{array}{l}42,3 \\
57,7\end{array}$ & $\begin{array}{l}39 \\
60\end{array}$ & $\begin{array}{l}39,4 \\
60,6\end{array}$ & 0,654 \\
\hline \multicolumn{8}{|c|}{ *: Bu gruptaki alerjenlerden en az birine karşı duyarlılık varlığı } \\
\hline \multicolumn{8}{|c|}{$\begin{array}{l}\text { Tablo 5. Alerjik astım, astım + alerjik rinit, astım + alerjik rinit + alerjik konjonktivit tanılı olgularda alerjen duyarlılıklarının } \\
\text { dağılımı }\end{array}$} \\
\hline \multirow[t]{2}{*}{ Alerjenler } & \multicolumn{2}{|c|}{$\begin{array}{l}\text { Astim } \\
(\mathrm{n}=313)\end{array}$} & \multicolumn{2}{|c|}{$\begin{array}{l}\text { Astım ve alerjik rinit } \\
(\mathrm{n}=246)\end{array}$} & \multicolumn{3}{|c|}{$\begin{array}{l}\text { Astım ve al. rinit ve al. } \\
\text { konjonktivit }(n=71)\end{array}$} \\
\hline & $\mathrm{n}$ & $\%$ & $\mathrm{n}$ & $\%$ & $\mathrm{n}$ & $\%$ & $\mathrm{p}$ \\
\hline A ğaç polenleri genel* & 45 & 14,3 & 54 & 22,0 & 22 & 31,0 & 0,002 \\
\hline Çimen polenleri genel* & 123 & 39,3 & 141 & 57,3 & 45 & 63,4 & $<0,001$ \\
\hline Tahıl polenleri genel* & 97 & 30,9 & 124 & 50,4 & 40 & 56,3 & $<0,001$ \\
\hline Yabani ot polen genel* & 36 & 11,5 & 67 & 27,2 & 22 & 31,0 & $<0,001$ \\
\hline Akar genel* & 244 & 77,7 & 176 & 71,5 & 47 & 66,2 & 0,062 \\
\hline Mantarlar genel* & 36 & 11,5 & 36 & 14,6 & 9 & 12,7 & 0,546 \\
\hline Kedi ve/veya köpek & 26 & 8,3 & 49 & 19,9 & 13 & 18,3 & $<0,001$ \\
\hline Hamam böceği & 8 & 2,6 & 25 & 10,5 & 3 & 4,2 & 0,001 \\
\hline
\end{tabular}


Pinus silvestris (\%1) duyarlılıkları saptanmıştır. Sadece alerjik astımı olan bu grupda inhalan alerjenler arasında en sık olarak akar alerjenlerine duyarlılık $(\% 77,7)$ saptandığı gözlendi. Akarları sırasıyla çimen polenleri \%39,3, tahıl polenleri \%39,3, yabani ot polenleri \%11,5, mantarlar \%11,5 duyarlılık oranları ile takip ediyordu. En düşük duyarlılık varlığı oranı ise hamam böceği duyarlılı̆̆ı idi $(\% 2,6)$ (Tablo 5).

Alerjen duyarlılıklarının dağılımı tanılara göre 3 gruba ayrılarak incelendiğinde; ağaç polen genel duyarlılık oranlarının sadece alerjik astımı olan olgularda \%14,3 iken, alerjik astım + alerjik rinit grubunda daha yüksek olarak \%22 oranında, alerjik astım + alerjik rinit + alerjik konjonktivit tanılı olgularda ise en yüksek oranda (\%31) saptandı (alerjik astımlı grup ile alerjik astım + alerjik rinit grubu arasında $\mathrm{p}<0,02$, astımlı grup ile alerjik astım + alerjik rinit + alerjik konjonktivit grubu arasında $\mathrm{p}<0,001)$ (Tablo 5). Alerjik astım + alerjik rinit grubu ile + alerjik astım + alerjik rinit + alerjik konjonktivit grupları arasında ise ağaç polen genel duyarlılı̆̆1 açısından anlamlı farklılık saptanmadi $(\mathrm{p}=0,116)$. Akar ve mantar grubu alerjen duyarlılığı için ise tanı gruplarına göre istatistiksel anlamlı farklılıklar mevcut değildi (alerjik astım ile alerjik astım + alerjik rinit grubu ve alerjik astım + alerjik rinit + alerjik konjonktivit grupları arasında sirasıyla $\mathrm{p}=0,062$, 0,546) (Tablo 5). Alerjik astıma, alerjik rinit ile alerjik konjonktivitin eşlik ettiği 2 grupta da; çimen polenleri, tahıl polenleri, yabani ot polenleri duyarlılık oranlarının sadece alerjik astım tanılı gruba göre istatistiksel anlamlı daha yüksek oranlarda bulunduğu saptand $1(\mathrm{p}<0,001)$. Alerjik astım + alerjik rinit grubu ile astım + alerjik rinit + alerjik konjonktivit grupları arasında ise çimen polenleri, tahıl polenleri, yabani ot polenleri genel duyarlılığ 1 oranları açısından anlamlı farklılıklar saptanmadı $(\mathrm{p}>0,05)$.

\section{Tartışma}

Alerjik hastalarda inhalan alerjen duyarlılıkları bölgesel, iklim, bitki örtüsü, coğrafik vb. çevresel faktörlerle değişkenlikler göstererek değişen oranlarda bildirilmektedir (17). Astım semptomlarını genel olarak en sık tetikleyebildiği bildirilen alerjenler akarlar, polenler ve mantar sporlarıdır. A ğaç polenlerinin diğer inhalan alerjenlere göre astım semptomlarına daha seyrek olarak etken olabileceği bildirilmekle birlikte, çocukluk çağı alerjik astımlı populasyonlarda ağaç polen duyarlılığ 1 görülme sıklığ 1 hakkındaki veriler diğer inhalan alerjenlere göre daha azdır.

$\mathrm{Bu}$ çalışmada Bursa bölgesinde atmosferinde de bulunduğu (6) bildirilen 6 ayrı ağaç polen alerjeni olan Olea europeae (zeytin), Alnus glutinosa (kızıl ağaç), Platanus acerifolia (çınar), Corylus avellena (fındık), Betula veruccosa (huş ağac1), Pinus silvestris (sar1 çam) alerjenlerinin alerjik astımlı çocuk olgularda duyarlılık oranları konusunda optimal sonuçlara ulaşmak amaçlanmıştır.

Çocukluk çağında astım, önemli oranlarda alerjik rinit ve/veya alerjik konjunktivit ile birlikte görülmektedir ve bu birliktelik birçok çalışmada saptanan alerjen duyarlılığı sonuçlarını da etkilemektedir. Bu nedenlerle çalışmamızda özellikle deri prik testleri ile alerjik astım tanısı alan astımlı olgulara odaklanarak, ayrıca sadece alerjik astımı olan olgularda (alerjik rinit ve/veya alerjik konjonktivit eşlik etmeyen) olgu grubunda da ağaç polen duyarlılıklarını araştırmak amaçlanmıştır. Çalışma popülasyonundaki olgularda deri prik testlerinde karışım alerjen ekstreleri yerine, daha ayrıntılı sonuçlara ulaşabilmek amacıyla tüm alerjenler tek alerjen olarak çalışılarak deri prik testleri gerçekleştirilmiştir.

$\mathrm{Bu}$ çalışmada Bursa bölgesinde ilk ayrıntılı veri olarak; alerjik astımlı dışında eşlik eden başka alerjik hastalığı olmayan çocuk olgularda test edilen 6 ayrı ağaç polen alerjeni; Olea europeae (zeytin), Alnus glutinosa (kızıl ağaç), Platanus acerifolia (çınar), Corylus avellena (fındik), Betula veruccosa (huş ağac1), Pinus silvestris (sarı çam) en az birine karş1 duyarlılık oranı dikkate değer bir oranda $(\% 14,3)$ saptanmıştır. Aynı hasta grubunda, bölgemizde Olea europeae polenine karşı duyarlılığın ağaç polen alerjenleri içinde en sik rastlanan duyarlılık olduğu saptanmıştır.

Türkiye'de farklı bölgelerde alerjik solunum yolu hastalığ 1 olan olgularla yapılmış çalışmalarda alerjen duyarlıkları incelenmiştir. Alerjik solunum yolu şikayetleriyle incelenen veya astım ve alerjik rinitli olgularda deri prik testleriyle çeşitli inhalan alerjen duyarlılıkların araştırıldığı çalışmalar içinde rutin olarak karışım veya tek alerjen olarak çalışılan ağaç polen duyarlılıklarının da saptanmış olduğu duyarlılık oranlarının bölgelere değişen rakamlarda olduğu görülmektedir. Ankara'da alerjik solunum hastalığ şüphesi olan (2-18 yaş) 2547 çocukta deri prik testleri sonuçlarını geriye dönük olarak analiz edildiğinde, 
ağaç polen alerjenleri Corylus avellana \%1,8, Betula alba \% 1,7, Populus alba \% 1,6, Platanus vulgaris \%0,7, Olea europaea \%1,1, oranlarında bildirilmiştir (18). İzmir'de 2003 yılında, astım+alerjik rinitli çocuk ve erişkin hastalarda tüm alerjenlerin retrospektif olarak tarandığ 1 çalışmada ağaç karışımı-1 alerjenleri (Alnus glutinosa, Corylus avellana, Populus alba, Ulmus scabra, Salix caprea) ile \% 14, ağaç karışımı-2 (Betula verrucosa, Fagus silvatica, Quercus robur, Platanus orientalis) ile \%17 oranında duyarlılık saptandı̆̆ 1 bildirilmiştir (19). Elazığ'da 5-18 yaş arasındaki 786 astımlı çocukta (\%55,8'inde ek olarak alerjik rinit mevcut olan) kızılağaç, kavak, söğüt, fındık, karaağaç polen karışımı duyarlılığ $\% 10,1$; huş, meşe, çınar, kayın polen karışımı duyarlılığı \%7,9; kavak ağacı poleni duyarlılığı \%4,1, söğüt agacı poleni duyarlılığ 1 $\% 3,8$, çınar ağacı poleni duyarlılığ $\% 2$ ve çam ağac1 poleni duyarlılığ 1 ise $\% 1,5$ olarak bildirilmiştir (20). Edirne'de solunum yolu alerjisi olan 4-17 yaş 539 çocukta (\%77,9'u atopik) genel alerjen taraması çalışmasında astımlı çocuklarda çeşitli ağaç polen alerjenlerine ayrı ayrı oranlarda duyarlılık $(\% 0,3-4,5)$ olarak bulunmuş, ayrıca bizim çalışmamıza benzer şekilde alerjik rinitli olgularda astımlı çocuklara göre daha yüksek oranlarda ağaç polenleri ve çimen, tahıl, yabani ot polenleri duyarlılıkları saptandığ 1 bildirilmiştir (21). Ankara'da 236 astımlı çocukta retrospektif olarak alerjen duyarlılıklarının araştırıldığ 1 yeni bir çalışmada ise deri testi sonuçlarına göre en az bir alerjene karşı duyarlılık sıklığg $\% 42.6$ bulunmuş, ağaç polen karışımları huşgiller [Betula alba, Alnus glutinosa, Corpinus betulus, Corylus avellana], zeytingiller [Olea europa, Ligustrum vulgare, Fraxinus excelsior], söğütgilller [Populus alba, Salix caprea] ile astım grubu çocuklarda $\% 3,7$, astım+alerjik grubu çocuklarda \%8,2 oranında ağaç polenlerine duyarlılık bildirilmiştir (22).

Ağaç polen genel duyarlılığının ve diğer polen duyarlılıklarının çocukluk çağında yaş artışına paralel anlamlı bir artış gösterdiği bu çalışmada görülmüştür. Ayrica çimen polenleri, tahil polenleri ve yabani ot polenleri genel duyarlılık oranlarında da benzer şekilde yaş ile birlikte belirgin bir artış bulunmuştur. Çocukluk çağı içinde genel olarak yaş artışı ile birlikte inhalan alerjenlere duyarlılık saptanma oranlarının artışı bilinmektedir (23). Ankara'da yapılan çalışmada 2-18 yaş çocuk ve adolesanlarda deri prik testleri sonuçları incelendiğinde, 2-5 yaş, 6-11 yaş, 12-18 yaş gruplarında inhalan alerjenlerin ve özellikle polen duyarlılığının yaş ile birlikte arttığı bildirilmiştir (18). Adana'da çocuklarda yapılan benzer bir çalışmada da polen duyarlılıklarının yaşla birlikte artış gösterdiği bildirilmiştir (24). İtalya'da astımlı hastaların 1-3 yaş, 4-6 yaş, 7-9 yaş, 10-17 yaş olmak üzere 4 gruba ayrılarak incelendiği çalışmada polen duyarlılığı görülme oranlarının yaşla birlikte arttığı saptanmıştır (25). Benzer şekilde Güney Kore'de okul çocukları ve adolesanları kapsayan bir çalışmada da polen duyarlııı̆ııın yaşla birlikte arttığı bildirilmiştir (26).

Alerjen duyarlılığı çoğu kez birkaç inhalan alerjene karşı birlikte duyarlılanma şeklinde görülmektedir, atopik bireylerde çimen polenleri, tahıl polenleri, ağaç polenleri ve yabani ot polenleri duyarlılıkları aynı olguda birlikte bulunabilen alerjen duyarlılıklarıdır (22). Bu çalışmada da alerjik astımlı olgularda ağaç polen genel duyarlılığı (en az bir ağaç alerjenine duyarlılık) varlığında; çimen, tahıl ve yabani otlar polen genel duyarlılıklarının yüksek oranlarda ve birlikte bulunduğu görülmüştür.

Çalışmamızda alerjik astıma, alerjik rinit ve/veya konjonktivit eşlik eden olgularda polen (çimen, tahıl, ağaç, yabani ot) duyarlılıklarının anlamlı olarak daha yüksek oranlarda olduğu saptanmıştır. Bu sonuçlarla benzer şekilde Ay ve ark. tarafından Ankara'da 236 astım tanılı çocuk ile yapılan bir çalışmada da astıma alerjik rinit eşlik eden olgularda polen duyarlılıkları daha sık saptanmıştır (22). İzmir'de 5055 çocuk ve erişkin olguyu kapsayan bir çalışmada da astımlı olgulara göre alerjik rinitli olgularda daha yüksek oranda çeşitli polen duyarlılıkları saptandığı bildirilmiştir (27). Li ve ark. tarafından Çin'de yapılan bir çalışmada da benzer şekilde alerjik rinitin eşlik ettiği astımlı olgularda polen duyarlılığ yüksek saptanmıştır (28). Alerjen duyarlılıkları gelişimi çevresel faktörlerden de etkilenmektedir, genel olarak alerjik rinit ve/veya alerjik konjonktivit olgularında polen duyarlılığının daha sık olarak görülebildiği bildirilmektedir $(21,27,28)$. Patogenezi çok iyi bilinmemekle birlikte, çevresel faktörler, atmosferdeki polen bulunma miktar veya süreleri, polen çaplarının diğer sık görülen inhalan alerjenlere nispeten daha büyük çapta olması ve bu nedenlerle çeşitli bitki polen maruziyetinin özellikle üst solunum yollarında klinik tablo ve semptomlara yol açabilmelerinin bu durumu açıklayabileceği düşünülmektedir. 


\section{Çalışmanın Kısıtlılıkları}

Çok sayıda hastanın dahil edildiği çeşitli alerjen duyarlılıklarını araştıran geniş çalışmalarda yaygın alerjenler içinde en sik alerjik duyarlılığa sahip olduğu bildirilen alerjenler araştırılabilmektedir. Bu çalışmada da ağaç polen duyarlılığ 1 araştırılırken Bursa bölgesinde atmosferde görüldüğü bildirilen ve çocukluk yaş grubunda en sık alerjen duyarlılığa yol açtı $\breve{1}$ bildirilen alerjenler kullanılmıştır. Astımlı olgularda daha düşük oranlarda saptanabileceği bildirilen diğer bazı ağaç polen alerjenlerinin de eklenmesiyle genel toplam duyarlılık oranlarında bir miktar artış saptanabileceği değerlendirilmiştir. Ayrıca bu çalışmanın tek bir merkeze başvurmuş olan hastalar arasında yapılmış olması da bir kısıtlılık olarak belirtilebilir.

\section{Sonuç}

Alerjik astımlı çocuklarda bölgemizde ilk kez detaylı olarak ağaç polen alerjenleri duyarlılığı konusunda elde edilen bu verilere göre ağaç polen alerjenlerine duyarlılık (en az bir ağaç alerjenine duyarlılık) oranı \% 17,7 olarak saptanmıştır. Alerjik astımlı çocuklarda en sık duyarlılığın akarlara karşı olduğu $(\% 75,0)$, daha sonra ise siklık sirasiyla çimen polenleri, tahıl polenleri, ağaç polenleri, yabani ot polenleri, kedi ve/veya köpek alerjenleri, mantar sporları ve hamam böceğine karşı alerjik duyarlılık olduğu tespit edilmiştir. Ağaç polen alerjenlerine duyarlılık oranları yaş ile paralel artış göstermektedir. Ağaç polen genel duyarlılık oranının sadece alerjik astım tanılı olgularda \%14,3 iken, alerjik astım + alerjik rinit grubunda, alerjik astım + alerjik rinit + alerjik konjonktivit tanılı olgularda ise anlamlı daha yüksek oranlarda var olduğu bulundu. Çocukluk yaş grubunda alerjik astımlı olgularda ağaç polen duyarlılığının akarlar, çimen polenleri, tahıl polenlerinden sonra dördüncü siklık sırasında saptandığını da gösteren bu çalışmadan elde edilen verilerin, hastaların tanı ve tedavi yaklaşımlarında göz önünde bulundurulmasının faydalı olacağı değerlendirilmiştir.

\section{Etik}

Etik Kurul Onayı: Çalışma için Bursa Uludağ Üniversitesi Tıp Fakültesi Klinik Araştırmalar Etik Kurulu'ndan onay alınmıştır.
Çıkar Çatışması: Yazarlar tarafından çıkar çatışması bildirilmemiştir.

Finansal Destek: Yazarlar tarafından finansal destek almadıkları bildirilmiştir.

\section{Kaynaklar}

1. GINA, Global strategy for asthma management and prevention. 2017. Chapter 1 Definition, description, and diagnosis of asthma. www.ginasthma.org.

2. Burbach GJ, Heinzerling LM, Edenharter G, Bachart C, Bindslev-Jensen C, Bonini S, et al. GA2LEN skin test study II: clinical relevance of inhalant allergen sensitizations in Europe. Allergy 2009;64:1507-15.

3. Oksel C, Custovic A. Development of allergic sensitization and its relevance to paediatric asthma. Curr Opin Allergy Clin Immunol. 2018;18:109-16.

4. Liu AH, Martınez FD, Taussig LM. Natural history of allergic diseases and asthma, in Leung DYM, Sampson HA, Geha RS, Szefler SJ (ed): Pediatric Allergy. St. Louis: Mosby-Year Book Inc., 2003, pp 10-22.

5. Bıçakçı A, Altunoğlu MK, Bilişik A, Sevcan Ç, Canıtez Y, Malyer H ve ark. Türkiye'nin atmosferik polenleri. Asthma Allergy Immunol 2009; 7:11-7.

6. Bıçakçı A, Tatlıdil S, Sapan N, Malyer H, Canıtez Y. Airborne pollen grains in Bursa, Turkey, 1999-2000. Ann Agric Environ Med 2003;10:31-6.

7. Bıçakcı A, Tosunoğlu A, Saatçığlu G. Allergenic Platanus (plane tree) pollen concentrations in Turkey. Asthma Allergy Immunol 2015; 13:76-89.

8. Bıçakçı A, Altunoğlu MK, Bilişik A, Sevcan Ç, Canıtez Y, Malyer $\mathrm{H}$ ve ark. Türkiye'nin atmosferik polenleri. Asthma Allergy Immunol 2009; 7:11-7.

9. Bıçakcı A, Tosunoğlu A, Saatçığlu G. Allergenic Platanus (plane tree) pollen concentrations in Turkey. Asthma Allergy Immunol 2015;13:76-89.

10. Biçakcı A, Altunoğlu MK, Tosunoğlu A, Çelenk S,Canıtez Y, Malyer H, Sapan N. Allergenic airborne Olea (olive) and Fraxinus (ash) polen concentrations belonging to the Oleaceae family in Turkey. Asthma Allergy Immunol 2009;7:133-46.

11. Holgate ST. A brief history of asthma and its mechanisms to modern concepts of disease pathogenesis. Allergy, Asthma Immunol Res. 2010;2:165-71.

12. Atkins D, Leung DYM. Diagnosis of Allergic Disease. In: Kliegman RM, Behrman RE, Jenson HB, Stanton BF (eds.). Nelson Textbook of pediatrics. 19th ed. Saunders Elsevier, 2015. 764-8.

13. Boner AL, Martinati LC. Diagnosis of asthma in children and adolescants. Eur Respir Rev 1997;7:3-7.

14. Carr WW. Improvements in skin-testing technique. Allergy Asthma Proc 2006;27:100-3.

15. GINA, Global strategy for asthma management and prevention updated 2010. Chapter 2 Diagnosis and classification. https:// ginasthma.org/wp-content/uploads/2019/01/2010-GINA. pdf).

16. Eigenmann PA, Atanaskovic-Markovic M, O’B Hourihane J, Lack G, Lau S, Matricardi PM, Muraro A, et al. Testing children for allergies: why, how, who and when. An updated statement of the European Academy of Allergy and Clinical Immunology 
(EAACI) Section on Pediatrics and the EAACI-Clemens von Pirquet Foundation. Pediatr Allergy Immunol 2013: 24: 195-209.

17. Bousquet PJ, Chinn S, Janson C, Kogevinas M, Burney P, Jarvis D. Geographical variation in the prevalence of positive skin tests to environmental aeroallergens in the European Community Respiratory Health Survey I. Allergy 2007;62:301-9.

18. Şahiner UM, Civelek E, Yavuz ST, Büyüktiryaki AB, Tuncer A, Şekerel BE: Skin prick testing to aeroallergen extracts: what is the optimal panel in children and adolescents in Turkey? Int Arch Allergy Immunol 2012;157: 391-8.

19. Tezcan D, Uzuner N, Sule Turgut C, Karaman O, Kose S. Retrospective evaluation of epidermal skin prick tests in patients living in Aegean region. Allergol Immunopathol 2003;31: 22630.

20. Kılıç M, Taşkın E. Alerjik Astımlı Çocukların Klinik Özelliklerinin ve Risk Faktörlerinin Değerlendirilmesi. Fırat Tıp Derg/Firat Med J 2015; 20(4): 199-205.

21. Yazicioglu M, Oner N, Celtik C, Okutan O, Pala O. Sensitization to common allergens, especially pollens, among children with respiratory allergy in the Trakya Region of Turkey. Asian Pasific J Allergy Immunol 2004;22:183-90.

22. Ay S, Civelek E, Kınık Kaya E, Güvenir H, Mısırlığlu ED, Toyran M,ve ark. Astımlı ve Astım-Alerjik Rinit Birlikteliği Olan
Çocuklarda Deri Testi Sonuçlarının Değerlendirilmesi. Türkiye Çocuk Hast Derg/Turkish J Pediatr Dis 2017;3:153-8.

23. Moral L, Roig M, Gadre J, Alós A, Toral T, Fuentes MJ. Allergen sensitization in children with asthma and rhinitis: marked variations related to age and microgeographical factors. Allergol Immunopathol (Madr) 2008;36:128-33.

24. Şaşihüseyinoğlu AŞ, Kont Özhan A, Serbest Mark. Çocukluk Yaş Grubunda Deri Testi ile Allerjen Duyarlılığının Dağılımı. Asthma Allergy Immunol. 2017;15:43-8.

25. Verini M, Rossi N, Verrotti A, et al. Sensitization to environmental antigens in asthmatic children from a central Italian area. Sci Total Environ. 2001;270:63-9.

26. Park SH, Lim DH, Son BK, et al. Sensitization rates of airborne pollen and mold in children. Korean J Pediatr. 2012;55:372-9.

27. Turgut CŞ, Tezcan D, Uzuner N, Köse S, Karaman Ö. Izmir Ili ve Çevresinde Allerjen Duyarlılık Oranları. SSK Tepecik Hast Derg 2003;13(1):19-24.

28. Li J, Sun B, Huang Y, Lin X, Zhao D, Tan G, et al. A multicentre study assessing the prevalence of sensitizations in patients with asthma and/or rhinitis in China. Allergy 2009;64:1083-92. 